\title{
Stocks Issued Registration System Reform's Influence on the Shell Resource Value
}

\author{
Chen Zhang \\ Economic School, Jinan University, Guangzhou, China \\ Email: 269285569@qq.com
}

How to cite this paper: Zhang C. (2017) Stocks Issued Registration System Reform's Influence on the Shell Resource Value. $i B u$ siness, 9, 1-12.

https://doi.org/10.4236/ib.2017.91001

Received: February 16, 2017

Accepted: March 18, 2017

Published: March 21, 2017

Copyright $\odot 2017$ by author and Scientific Research Publishing Inc. This work is licensed under the Creative Commons Attribution International License (CC BY 4.0).

http://creativecommons.org/licenses/by/4.0/

(c) (i) Open Access

\begin{abstract}
Since the establishment of China's securities market in 1990s, the stock issuing system has experienced many times of changes. In most of the time, the distribution mechanism was a kind of audit system, which led to many enterprises to list on queuing, which is combined with several times of IPO pauses, making it harder to go public. In such background, listing qualifications of public companies have become a scarce resource and shell trade has become popular. From 18, 2013, however, China central government had put forward registration system reform for the first time. The scarcity of shell resource started to be striking. A widely concerned question is that under the background of registration system reform, what changes will happen in the value of shell resources and how the shell resources will be traded. This article will combine the history with Chinese stock issuing system. Difference between Chinese and foreign. Shell resource value constitutes several influence factors. This article try to study how these factors will change and how shell resource value will be affected during and after the process of registration system reform, and provide some useful advice about how to handle these changes.
\end{abstract}

\section{Keywords}

Registration Reform, Shell Resource, Listing through Buying a Shell

\section{A Review of Stock Issuance Regulation}

\section{The Evolution of Issuance Regulatory Department}

The supervision department of stock issue market has experienced the evolution from People's Bank of China, the Central and Local Economic Restructuring Commission, Commission for Discipline Inspection and the Securities Commission of the State Council to other government departments. Until the establish- 
ment of China Securities Regulatory Commission and the Revocation of Securities Commission of the State Council, the rights of the securities market leading regulators began to be centralized and unified, forming a regulation system which was dominated by the China Securities Regulatory Commission and its dispatched institutions, combined with the Chinese Securities Association and the Shanghai and Shenzhen Stock Exchange for Auxiliary Supervision System. Core authority is the China Securities Regulatory Commission [1].

Looking at the composition of the regulatory body, we will find that stock issuance regulation institution in China was led by the government. Chinese government acts as the owner and manager of the state-owned assets at the same time [2]. Regulatory system is centralized and unified, reflecting the feature of "emerging and transition". Among them, the local offices of China securities regulatory commission (CSRC) is directly under the management of China securities regulatory commission, and the China securities Regulatory Commission has stronger control on it. According to the current laws, the responsibility and right of the exchange of the securities and industry association is not very clear.

1) Evolution of China's stock issuing supervision system

In general, the evolution of the Chinese stock issuance regulation system is a transformation from the examination and approval system to authorization system, which is a substantive change process from audit to the compliance audit. But from the point of the reform practice recent years in China, the establishment of the authorization has not gotten rid of the substantial review and value judgment of the examination and approval system regulation [2] [3].

a) Quota management stage 1993-1995

Under the quota management system, the securities regulatory authority will determine a sum of listing quota at first according to the requirements of national economic development and the situation of capital market at that time, then securities regulatory authority will distribute these quota to local government and departments in charge of different industry according to the economy status and future need of these regions and industries as well as the local government and the competent departments of industry. They finally determined which enterprise could issue shares. At this stage, the government determined the 10.5 billion quotas in total, and issued 5.5 billion shares in 1993, 5 billion shares in 1995. The competent departments of the provincial government or industry selected business to assign the quota, and then assigned it to enterprises in various provinces and cities. These enterprises needed to hand in application for issuing stock to China Securities Regulatory Commission. If the application is agreed by CSRC then they can issue stock. More than 200 enterprises issued stock in this stage and raise more than 400 million [4].

b) Index management stage 1996-2000

Quota allocation methods lead to various problems, in order to balance interests, take care of more enterprises which want to issue securities, provinces and cities, ministries limit the scale of issuance. However, it is not conducive to the 
development of large scale of enterprise; on the other hand it will lead to supply and demand in securities market. So the state changes the quota allocation to issue number, i.e., CSRC determines the issue number of enterprise and localities and ministries report the selected enterprise based on the issue number limit [5]. After the approval of securities issuance application l, the CSRC will determine the specific time of issuing according to the market situation. In this stage, the practice named "control the total number and set a limit", securities regulatory authority under the state council determine the number of issuing enterprise in a certain period, and then reported the number to the provincial government and industry management department, the provincial government or industry management departments within the above indicators recommended primary enterprises, securities enterprises for eligible primary agreed to report its offering formal review and filing materials. More than 200 enterprises issued stock in this stage and raise more than 700 million.

c) Authorization stage under the "Channel" 2001-2004

During the early period of authorization stage, after listed counselling work, the number of companies who subject to the listing conditions rockets to a high level, which release enormous stress to market. In order to adapt to this situation, the department concerned launched a complete set of measures "channel" under the authorization [5]. In March 2001 China implemented "channel" under the authorization; namely transmit issued enterprise number can be recommended to a public stock offering to the comprehensive securities. As long as the comprehensive broker has the qualification of lead underwriters, the broker can obtain 2 to 8 channel, based on the case it underwriting in 2000, a new comprehensive broker will have 2 channel number. The "channel" the broker has was the number of listing enterprise the broker can report. In this stage, there are more than 200 companies raised more than 2000 million yuan. In this stage the limit of listing number has not changed, but the channel system changed the past practice of administrative select mechanism, to a certain extent, the underwriters won the right of issuing enterprise selection and recommendation and take corresponding risk.

d) Authorization stage under the "Sponsor system"

The full name of the sponsor system is sponsor representative system. It is a kind of stock issuance regulation system that China's securities regulator is currently carrying out, the sponsor system consists of two parts, sponsors and sponsor, sponsors were those who satisfy certain conditions and qualifications, who have two or more sponsors of securities companies (or asset management company) can be a sponsor, and have the qualification for recommended enterprise offering. In terms of its essence, Sponsor system hopes that sponsor act as a "first gatekeeper" of securities issue, namely the sponsors, select listed companies with high quality in the process of insight, understanding, and diligently [4] [6].

Securities issue authorization stick to the principle of public and offer management department with the authority of certain key value judgment. This sys- 
tem provided investors the opportunity to independently determine through public information, also make institutional arrangement for management department to strictly control, can exclude some poor quality, and high risk company out of the stock market. It will provide double safeguard for the interests of investors to get help to reduce market risk, maintain the market stability and development.

However, there are two major defects: one is the value judgment that audit institutions hold may not exactly right, sometimes there will be a audit failure, and it makes originally qualified companies, particularly the high growth, high technology, high-risk companies issuing blocked, cannot raise working capital from the stock market in time. It will not only affect the enterprise production and management development, and beneath the securities issue market fair. Secondly, audit institutions carrying on the substantive examination in advance will give investors with false indication that the safety and profitability of issuing securities has been guaranteed, and thus give up independent judgment, this is not conducive to cultivate investors the ability to take risks.

This system is beneficial to promote the healthy development of the emerging stock market, more suitable for those markets with low quality investors, short securities market development history, and incomplete supervision system and criterion. It is worth noting that the purpose of the substantive review is not to replace the investor's own decisions. In the process of concrete implement of this system, management organization is necessary to adjust the scope of review, to relax standards according to the degree of maturity of the market and investors. Eventually this system means to give investors a value judgment and choice.

\section{The Comparison of Stock Issuance Regulation at Home and Abroad}

\subsection{Securities Regulation System Comparison with the Developed Country}

\subsubsection{Difference in Development Level of Stock Issuance Regulation}

Compared with China, the securities offering supervision system in developed country perform better the implementation, the rule of law, responsibility implement, and efficiency [7]:

Complete system: perfect information disclosure rules, strong maneuverability; this system attaches great importance to the company's dynamic information disclosure, and encourage predictive information disclosure and maintain high standards of accounting standards and strict audit procedures.

Strong implement: securities regulators in developed market economy countries will treat information disclosure law enforcement as a daily priority. As for the securities information disclosure violations that may occur, there are perfect, highly effective accountability mechanism make illegal behavior person take corresponding legal responsibility through administrative, civil and criminal procedures.

The rule of law: securities regulator in the developed market economy coun- 
tries has always emphasized that offering information disclosure comply with the specification of an organic whole, information disclosure regulation law enforcement not fluctuates according to management policies.

High efficiency: Britain is trying to reduce the cost of equity offerings in disclosure for the purpose of reform; "The financial services modernization act" also emphasizes reduce regulatory burdens in US; Most developed market are trying to improve the efficiency of information disclosure through the Internet and other new technology.

China securities market has made rapid development, but the gap is still large compared with developed market economy countries. Stock issuance regulation system in China has the feature of government dominant, although China was carrying on authorization, there are essential differences with foreign system which was based on the registration system of market selection.

\subsubsection{Comparison of Information Disclosure}

Information disclosure regulation generally has two goals: one is increasing effective deterrent effect of current securities regulation system; second is to provide relief and compensation for infringement investors and fully protect the interests of investors [2]. All countries look investors' interests protection as the basic goal and basic principles of securities legislation. China is not exceptional, the securities law, general or specific information disclosure system all look the interests of the investors protection as a fundamental goal. In western countries, the intermediary institutions and securities regulators supervise the information disclosure of listed companies together, to ensure the authenticity and completeness of the report issued. But in China, intermediary agencies worked with the listed company on the question of the authenticity of information disclosure to confront regulatory department, so that the regulation and the power of the regulated changes to a large extent. There is no doubt that this is greatly increased the difficulty of the regulation.

From the point of offering information disclosure system construction, China has preliminary established a more scientific and reasonable system framework [3]. Substantive law norms were in line with international standards but part of the specification requirements of the implementation of the program remains to be further improved. From the perspective of the actual effect of information disclosure law enforcement and supervision, there are large gap between China and developed economy countries but we already did a good job compared with other emerging securities market. Authorization, the stock issuance examination system in China, has made considerable achievements in strengthening information disclosure, but phenomenon like false packaging always cheat listed always occurring, some of the reason is that intermediary institutions don't adapt to the new system, but the most important thing is the lack of "good faith" concept. Because of the lack of "good faith" concept, securities firms, accounting firms, law firms and other intermediary personnel and quasi person of listed companies is not active in accordance with market principles and rules. In order to 
make disclosure of information true, accurate and complete, full, they can even create a "real" information, such as change the use of funds.

\subsubsection{Difference in Social Credit Foundation}

As an important part of market economy system, the supervision and law enforcement efficiency of Chinese securities market is affected by the political system, economic system and the restriction of many factors such as social environment. The securities market from domestic actual cannot achieve the rule of law and regulations because the modern market economy based on the rule of law is not yet fully established.

In traditional legal culture, there is significant difference between China and western countries, western countries have a long history of the rule of law tradition, its legal culture is typical of the rule of law culture; China has more than two thousand years of feudalism history, that country is rely on people to governance, law is only a means to treat people the tools and. China is still at the initial stage of the rule of law and credit society, the society as a whole legal system, market economic order has not yet fully established, thus restricted the supervision and regulation efficiency of Chinese securities market. In Chinese tradition culture, they lack the idea of credit in commodity trade. Commodity economy "good faith" concept has survived and developed in the soil of the western culture for thousands of years, and they cultivate it only for twenty years [2] [8]. Maybe they can give offenders quick education of dishonesty by harsh punishment. In the long run, the smooth implementation of authorization must have a cultural environment of "good faith" as a solid foundation. Therefore, from the perspective of honesty cultivation, there is a long way to go for the real authorization.

\section{Theory of Shell Resource}

\subsection{Connotation of Shell Resource}

As for the connotation of shell resource value, domestic theoretical point of view can be roughly divided into two parts, namely the broad and narrow sense of shell resource value [9]. In the broadest sense of the term, shell resource value refers to the value of the listed company as a whole, scholars who in favor of the idea believe that the value of shell resources should include all of the net assets of listed companies and the value of intangible assets acquired listed dominance; Narrow shell resource value theory treat shell as a kind of intangible assets of listed companies and came from listing qualifications. It means a collection of advantage in refinancing and enterprise image publicity and preferential policies to support, the collection value is the narrow sense of shell resources value.

Scholars who hold broad point of view think the company has a value not only because of its listing qualifications, but also because of its assets as a company ; Narrow argument is that the value of the company itself does not constitute an important part of the shell resource value, shell resource is valuable thanks to the advantages brought by the listing qualification, this point of view is accord with 
the present situation of China mostly shell corporate flat operating performance and the company's small net assets.

The number of researchers who hold generalized view of shell resource value is relatively small, researchers Zhang Hailin (2000) argue that the shell resource value is the basis of back-door trading pricing, the value is reflected in the shell company as the value of an ordinary company, known as the enterprise value, the second is as a public company, the listing qualifications, the value of the many advantages of both is the sum of the value of shell resources, after the part is in fact the so-called special shell resource value [9]; Liu Liying (2009) argue that the shell resource is unique to a listed company to appear on the market as the form, the equity capital as the connotation of special economic resources, and through this kind of special economic resources can connects the real economy and virtual economy effectively [4]; Yu Guochang (2012) argue that equity is the external form of shell resources, the "connotation" is its own assets, whose value depends on the size of the shell resource scarcity and back-door company's own development ability [6].

More researchers agree with the narrow shell resource value connotation, Zhao Changwen (2001) argues that the general cause of shell resource is a bad time in industry, business management, etc., special reason lies in the different system background, the emergence of a shell company is the inevitable outcome of the securities market development, points out that "the qualifications of the listed company or the brand of listed companies is the shell [10]. Zhou-jun (2001) argues that value of listed companies shell is part of the value after the listing of the intangible assets; Chen Yongzhong (2004), puts forward the concept of market property and subdivided it into market financing and market trading rights, he defined shell resource value as the value of the property market [11]; Wang Xingyu (2002) argues that shell resource is the qualification that trade in the market, shell resource value is the value of the deal qualification in the secondary market [12]. Sun Xiaoyan (2008) defined shell resource value as the value of the opportunity for future earnings growth value [5]; From the perspective of options analysis options and the characteristics of shell resources, Xu Chenggang (2009) thus thinks of shell of the securities market in China is in essence a disguised options [13]; in Yang's opinion (2004), shell resource is a kind of intangible assets that listed qualifications brought, is derivative products of a specific system [14]; Ms. Zhu (2012) regarded the listed company's shell resources as a kind of financing rights, its value is the present value of the benefits to this kind of financing rights can brought in the future [15].

We can make an easy example to better understand the meaning of these two different concepts of shell resource. We can look listed a company as a noble with specific identity. This identity is the listing identity and other assets besides this identity refers to those land and houses in this noble's home. People who hole the generalized view of shell resource value believe that the value of shell company should including not only the listing identity but also those land and houses in this noble's home. However, narrow concept supporters thought shell 
companies refer to those companies with low revenue and even minus profit. In their concept, the shell company is a broken-down noble, so the only valuable assets are the listing identity.

\subsection{Constitution of Shell Value}

The shell of listed companies is the material carrier of shell resource, its value equals the value of the asset plus the value of the shell. As a kind of resource, shell resource in China's securities market can exist as a kind of resources because of its special value, its value mainly supported by the following two points:

First shell resource is profitable: listed companies in China can enjoy many privileges granted by the government, such as the right to list and low-cost financing, tax preferential rights, etc., and China securities market also has its particularity: the state-owned shares in listed companies of absolutely holding status, caused bankruptcy difficult phenomenon of listed companies. Listed companies is to get a piece of "gold" from death no matter how serious violation behavior. The weakest listed company can also sell listed qualification through restructuring to other enterprises. There were small number of companies that quit the market in Chinese securities market since its establishment which means the listed company is almost a lifetime. All of these monopoly profits make shell resource has the profitability [16] [17].

Secondly, shell resource is scarce: this is the important reasons for the formation of its value, the company that wants to gain the profitability, need to obtain the listed qualification in the first, but under the current stock issuance of authorization, the qualification for listing is not easy to obtain. First of all, the management of the securities market in China has a strict access system: securities issuing carry on strict authorization, requests the issuer not only subject to full disclosure of the real situation, and in accordance with relevant laws and essential conditions prescribed by the securities regulatory authority [18]. Such strict conditions makes a large number of companies that trying to list rejected at last. Moreover, even if the enterprise can achieve a series of review standards, the government strictly controls the issuance of shares, each queuing up to hundreds of companies. Time cost is huge. So many private enterprises that eager to develop turned to list by buying a shell, which makes the shell resource scarce resources [19].

\section{Shell Resource under Registration System}

\subsection{During the Reform: The Shell Value Still Exist Because of Reasons Below}

First, the listing channel is not smooth: there are many public reserve army, by the end of 2013, China's a-share market experienced eight IPO moratorium n just 23 years of the birth and total suspended time is four and a half year. Artificial control of IPO moratorium is unfavorable to the market to play the function of financing. After the restart of IPO in January in 2014, a total of 48 enterprises issued new share and then IPO experience another IPO pause. Until April 7, 
2014, a total of 28 companies' termination of IPO audit and there are 669 companies still in the queue for an IPO in Shanghai and Shenzhen securities market. At present, listing channel is still not smooth and the threshold of listing is still high, so it's difficult to digest such large number of listed reserve in the market through the IPO [8].

Second, compared with direct listed, backdoor listings is more flex and high cost of time make backdoor listings popular again, Because there is no need for road shows and inquiry, even if the shell conditions is equivalent to IPO, the advantage is still evident compared with complex process and long time of IPO [3] [8].

For backdoor restructuring enterprises, from the listed company restructuring plans to the final approval to complete, it generally takes only a year, sometimes even only half a year to complete. In addition, the listed through buying a shell is also a more flexible operation, even the restructuring of listed companies was rejected by issuance examination committee, they can also continue to promote restructuring at the board of directors in the next day, by contrast, once IPO was rejected, they need to wait for 6 months to resubmit application.

Third, the strict enforcement of the delisting system need time to transfer, the original delisting system in China can be explained as this: listed company losses for three consecutive years are suspended, if continue to loss in the fourth year, the listing of its stocks will be terminated delisting condition, this makes listed companies to take advantage of regulatory loopholes through earnings management to implement the temporary turn round, caused the phenomenon of difficult delisting [20].

Whether a bad company can delisting or not is not determined by the market but mainly by the major shareholders of listed companies and local governments. In numerous of ST companies, there are nearly forty percent of the companies keep their listed position thanks to large subsidies from the local government.

In addition, in the process of delisting, there is no compensation for the interests of the investors and accountability mechanism, the delisting apparently caused damage to the interests of the investors, although the securities and futures commission has issued a "about reform and improve and strictly implement the several opinions of the delisting system of listed companies, but this act still need time to transition of its execution effect. Besides that, China still lack of related law and regulations about delisting companies listed, this affects the reform process of registration system, and thus make the shell resource is still valuable in the process operation.

All in all, the root reason that the shell value still exist during the reform is that there are still many barriers in the implement process of registration system reform. One of the main barriers is that China government's punishment towards securities crime is too light; the power of regulatory authorities and judicial departments is too limited. Another barrier is the immature information disclosure system and it is not rare to see false disclosure and performance fraud. 
As a result, the shell value will still exist until the registration reform was implemented complete in China because there are still lots of companies who are waiting for going public.

\subsection{After the Completion of the Reform: Shell Resource Value Will Gradually Downward, ST Class Shell Company Is Difficult to Protect Shell}

If China can finish registration system reform, it will be able to form a smooth channel of IPO, as well as the normalized, marketization, legalization of delisting mechanism, it makes the demand of shell resources drop markedly. When lost scarcity and profitability, the value of shell resource will drop sharply, especially the large shareholders' willingness to protect shell will be reduced, the bartender shell harder; On the other hand, investors who speculate in trash stock will receive a alert. In the long term, the value of shell resources will gradually downward [8].

\section{Conclusions}

This paper analyzes the effect of registration reform on the value of shell by reviewing the shell resource theory, combining with the concept of registration system. This paper argues that new distribution system of monopoly regulation is the essence reason for the formation of shell resource value; namely the value support of shell resources comes from the scarcity of listed qualifications, and the IPO threshold will be reduced under registration system; thus, shell resource value is closely related with the progress of registration system reform. The main contribution of the paper is that it combines the development process of securities auditing mechanism and the differences in China and foreign auditing mechanism and two different concepts about the meaning of "shell resource" to study the effect of registration reform on shell value. We make the definition of "shell" clear, which is the listing identity. Through these works, we can analyze the reasons why shell value still exists during the registration reform with solid theoretical basis.

In this paper, the research results show that the registration system needs a series of preconditions, and if these measures are not complete, the registration system is impossible to make the market play a real role. So the registration system will not happen overnight, there is still demand for shell resources during the process of reform and shell resources value will exist for a long time in the future. But after the formal implementation of registration system, it will be able to realize marketization, and the value of shell is inevitably dropping.

Our country is in economic transition period, and the uncertainty of the institutional environment is one of the important factors of enterprises to make decisions in the process of the reform of system of stock issuance registration, which brings some opportunities. But it's a great challenge to most of shell companies. A useful suggestion for those shell companies is that they should determine to maintain or activate delisting listed qualifications as soon as possible 
based on its own specific conditions.

The biggest limitation of this paper is that it doesn't provide a clear estimate about the specific process of registration reform, and it only points out that there will be several barriers during the reform but it fails to offer a quantitative analysis of how these barriers influence the reform.

\section{References}

[1] Shu, Z.Y. (2014) Domestic Listed Companies Shell Resource Value Factors Affecting Research. Beijing Jiaotong University, Beijing.

[2] Gu, H.J. (2006) China's Stock Issuance Regulation Research. Fudan University, Shanghai.

[3] Jiu, Y.H. (2016) Registration System Reform under the Shell Resource Trading Behavior Study. Journal of the Chinese Market, 7, 18-19

[4] Liu, L.Y. (2009) An Empirical Study of Factors Influencing the ST Company Shell Value. Chengdu University of Technology, Chengdu.

[5] Liu, Z.L and He, J.B. (2008) Based on the Empirical Research on Chinese Listed Companies Valuation KMV Model. Journal of Management Engineering, 1, 102107.

[6] Yu, G.C. (2012) ST Company Shell Resource Value Analysis. Anhui University of Finance and Economics, Anhui.

[7] Liu, L.C. (2003). Listed Companies Shell Resource Value of Fuzzy Clustering Evaluation-In Shanxi Province as an Example of Research. Journal of Quantitative Technical Economics, 5, 149-152

[8] Chen, Y.P. and Feng, J. (2015) Share Issue Registration System Reform's Influence on the Shell Resource. Journal of Accounting Friend, 3, 13-17

[9] Zhang, H.L. (2000) Back-Door Listing of Valuation Method. Journal of Joint-Stock Warp and Weft, 3, 30-32.

[10] Chen, Y.Z. (2004) Theory of Property Rights Market and listed Companies Shell Resource Value. Economist, 6, 96-102

[11] Zhao, C.W. (2001) Shell Resource Research: China’s Listed Company Merger and Acquisition Theory and Case. Southwest University of Finance and Economics Press, Chengdu.

[12] Wang, X.Y. (2001) "Shell Resource" of Listed Companies and Their Market Price Model. Journal of Economic System Reform, 2, 115-118

[13] Xu, C.G. (2008) The Value of Shell Resources in China Is Just another Option Research. Journal of modern business, 10, 10-11

[14] Yang, D. (2004) Shell Resource Value and the IPO Pricing Empirical Study. Journal of economist, 2, 32-35.

[15] Zhu, L. (2012) Restructuring Based on ST shell Resource Utilization Performance Research. Fudan University, Shanghai.

[16] Zhang, D.H. (2000) Listed Companies Shell Resource Shadow Price Analysis Model. Journal of Contemporary Economic Science, 7, 17-21.

[17] Chen, P.L. (1999) Back-Door Listing "Shell" Companies in the Value of Assessment. Journal of Economic, 12, 20-21.

[18] Peng, J. (2002) Back-Door Listing Transaction Price Determination and Cost Benefit Analysis. Journal of Yunnan Institute of Finance and Trade, 2, 31-35. 
[19] Wu, J.M. (2012) Based on the Shapely Value of Shell Resource Premium: An Empirical Study of Factors Affecting. Mathematical Statistics and Management, 1, 157-163

[20] Ren, Y. (2009) Shares of Listed Companies in China: An Empirical Study of Correlation between Financial Information. Thesis, Jiangxi University of Finance and Economics, Jiangxi, 12.

\section{Scientific Research Publishing}

Submit or recommend next manuscript to SCIRP and we will provide best service for you:

Accepting pre-submission inquiries through Email, Facebook, LinkedIn, Twitter, etc. A wide selection of journals (inclusive of 9 subjects, more than 200 journals)

Providing 24-hour high-quality service

User-friendly online submission system

Fair and swift peer-review system

Efficient typesetting and proofreading procedure

Display of the result of downloads and visits, as well as the number of cited articles Maximum dissemination of your research work

Submit your manuscript at: http://papersubmission.scirp.org/

Or contact ib@scirp.org 